\title{
ABORDAGENS PARA COCRIAÇÃO NO ENSINO DO DESIGN: reflexões sobre iniciativas no contexto da graduação e da pós-graduação
}

\author{
Lia Krucken, Dr. \\ Escola de Design | Universidade do Estado de Minas Gerais \\ lia.krucken@pq.cnpq.br \\ lara Mol, M.Sc. \\ Escola de Design | Universidade do Estado de Minas Gerais \\ iaramol.ed@gmail.com
}

Resumo: Este artigo busca promover uma reflexão sobre algumas abordagens de cocriação no ensino do design. Apresenta-se, como estudo de caso, experiências conduzidas em cursos de graduação e pós-graduação na Escola de Design da Universidade do Estado de Minas Gerais - UEMG, no período de 2012 a 2014. Destacam-se as ferramentas de design que são usadas nos processos de criação, desenvolvimento e apresentação das soluções pelos alunos. Como resultado, discutem-se alguns pontos críticos e questões em aberto levantados ao longo do processo de inovação colaborativa, visando contribuir para o entendimento das competências necessárias à formação de profissionais dinâmicos, que possam oferecer soluções contextualizadas ao cenário atual. Por fim, evidencia-se aspectos relacionados ao potencial de inovação social presentes nos projetos.

Palavras-chave: Cocriação, Processos Participativos, Pesquisa e Ensino em Design, Inovação Social.

\begin{abstract}
This article aims to reflect on some approaches to co-creation for design teaching. Presents, as a case study, conducted experiments in undergraduate and postgraduate studies at Escola de Design - UEMG, in the period 2012-2014. Noteworthy are the design tools that are used in the processes of creation, development and presentation of solutions by students. As a result, we discuss some critical issues and open questions raised throughout the process of collaborative innovation, aiming to contribute to the understanding of the skills necessary for the formation of dynamic professionals, who can offer solutions that best fit the current scenario. Finally, highlights aspects related to the potential for social innovation projects.
\end{abstract}

Keywords: Co-creation, Participatory Processes, Design Teaching and Research, Social Innovation. 


\section{INTRODUÇÃO}

A emergente necessidade de ampliação das competências dos profissionais envolvidos em projetos de design reflete a complexidade e o dinamismo do cenário contemporâneo. Daí resulta a busca do design por interagir, cada vez mais, com outras áreas, configurando uma colaboração inter e transdisciplinar e ampliando o potencial de soluções para determinadas questões de projeto. A ampliação do potencial de aplicação do design no contexto atual fez com que os profissionais, além de trabalharem individualmente desenvolvendo linguagens próprias a partir do uso criativo de ferramentas e técnicas de concepção, se reunissem em equipes e desenvolvessem as competências necessárias para solucionar não só desafios de negócios como também problemas sociais.

No contexto da sala de aula, a formação em design tende a reforçar o desenvolvimento de competências centradas no indivíduo, o que não é, muitas vezes, condizente com as necessidades atuais de um mercado complexo, exigente de soluções interdisciplinares e, portanto, competências relacionadas ao trabalho em equipe. Entende-se, dessa forma, a sala de aula como um ambiente propício e indicado ao aprendizado a partir de vivências e interações em grupos e pressupõe-se que o professor, além de responsável pela condução dessas práticas, é também o principal facilitador do processo de experimentação e colaboração por parte dos alunos.

Primeiramente apresentam-se algumas considerações teóricas fundamentais para o embasamento do trabalho, especialmente sobre abordagens participativas e cocriação em design. Na sequência, as iniciativas implementadas são descritas e avaliadas e apresenta-se uma breve análise sobre o método e as ferramentas utilizadas ao longo de todo o processo. Finalmente, expõe-se as considerações finais, que têm o propósito de não limitar a discussão sobre o tema, mas indicar novas questões de pesquisa e possibilidades que se delineiam a partir da experiência conduzida.

\section{REFERENCIAL TEÓRICO}

Questões relacionadas às competências essenciais que o design precisa desenvolver para atuar na sociedade contemporânea foram abordadas por diversos autores, dentre os quais destacam-se Manzini (2004), Thackara (2005), Teixeira (2012). Conforme aponta Manzini (2004, p. 20), os designers "têm que mudar seu perfil profissional, convertendo-se em operadores que atuam dentro de uma rede, assumindo o papel de provedores do processo de inovação". No mesmo sentido, Thackara (2005) aborda o "design em um mundo complexo", evidenciando a importância de modelos de ação colaborativos, contínuos e abertos, que incluam o usuário. $\mathrm{O}$ autor reforça a necessidade da integração do designer com agentes locais e cidadãos para desenvolver formas de inovação colaborativa, que resultam em novos serviços para a vida cotidiana. Estas considerações reforçam a necessidade de desenvolver competências que vão além de um âmbito profissional específico, relacionadas à interatividade, à habilidade de escuta e de ação em diferentes contextos, à gestão da informação, ao desenvolvimento coletivo, à análise sistêmica, dentre outras.

Tais competências reforçam o potencial de atuação do design para gerar inovações no âmbito social, em um contexto onde as pessoas estão buscando respostas mais efetivas para os grandes desafios da atualidade, especialmente nos países emergentes. Em seu conceito, a inovação social está ligada à capacidade que 
uma sociedade tem de solucionar seus próprios problemas e se relaciona com praticamente todas as questões que interferem e configuram essa sociedade de forma geral. Cipolla (2012) destaca o fato da palavra "social" designar tanto um meio quanto um fim: "como meio, indica que tais inovações são baseadas nas capacidades pessoais de seus participantes e em interações e parcerias inesperadas entre cidadãos, instituições, empresas e governos. E, como fim, "indica que o esforço social está direcionado a solucionar problemas comuns e amplamente reconhecidos aos quais empresas e soluções tecnológicas falharam em oferecer resposta".

A abordagem considerada neste artigo compreende a inovação social de forma ampla, como meio e também enquanto fim. Mais especificamente, pode ser compreendida como as novas ideias (produtos, serviços e modelos) que conseguem atender às necessidades da sociedade e ao mesmo tempo criar novas relações sociais ou colaborativas. Em outras palavras, é a inovação que gera ótimos resultados sociais e, simultaneamente, tem a capacidade de motivar os cidadãos à ação (MURRAY, CAULIER-GRICE, MULGAN, 2010).

Coaduna com essa abordagem o conceito de cocriação, uma vez que processos de interação e parceria são apontados como grande potenciais para inovação, especialmente quando envolvem cidadãos. $O$ conceito de cocriação surge no contexto da popularização da internet, no início do século XXI e em meio a uma crescente insatisfação dos consumidores com relação aos serviços e produtos oferecidos pelas empresas, de maneira geral. Os avanços da tecnologia da informação e da comunicação e seu potencial de fazer com que todos possam comunicar, alterou definitivamente a relação existente entre indivíduos e instituições. Além disso, a alta competitividade levou as instituições a voltarem o foco para a sua relação com os indivíduos (PRAHALAD; RAMASWAMY, 2004). Inicialmente por meio da internet, os consumidores passaram a exercer influência em todo o sistema operacional dos negócios. Insatisfeitos com as empresas e equipados com novas ferramentas começaram, assim, a co-criar valores juntamente com as empresas e conquistaram a possibilidade de adequar a experiência do serviço aos seus próprios contextos, unindo a definição do problema com sua própria resolução.

Em resumo, a cocriação é um ato de criatividade coletiva experimentado e realizado em conjunto por um grupo de pessoas e se trata de uma plataforma que coloca todos os participantes em um mesmo nível de hierarquia e grau de envolvimento com o projeto a ser desenvolvido. Sob a perspectiva do design, Nielsen, (2011) aponta que o processo de cocriação é conduzido através das ferramentas adequadas, com um planejamento para o processo de inovação e habilidade para dar forma às ideias. A cocriação no design considera que todas as pessoas possuem habilidade para criar, desde que seu processo seja facilitado e que sejam orientadas para tal. Além de possuírem conhecimento sobre suas próprias necessidades, os participantes fazem parte da geração coletiva de ideias, reunião de conhecimento e desenvolvimento do conceito. Dessa maneira, entende-se que a inovação está intrinsecamente relacionada à cocriação e pode ser facilitada por meio de um processo participativo.

É oportuno evidenciar algumas questões relacionadas ao termo cocriação. Como alguns autores apontam, as palavras cocriação e codesign, muitas vezes são usadas como sinônimos, apesar de seus diferentes significados. Para ambas, não existe definição nos dicionários. No entanto, algumas considerações podem ser feitas. 
Cocriação está relacionado à um processo de criação conjunta e traz a ideia de criatividade coletiva - ou seja, de um processo de troca entre pessoas, que pode gerar diversos tipos de resultados. Codesign, por sua vez, indica criatividade coletiva aplicada ao longo de um processo de design - "criatividade coletiva dos designers em colaboração", como apontam Sanders e Stappers (2008).

O fato é que "processos participativos" são descritos na literatura acadêmica com nomenclaturas diversas e sob a perspectiva de várias áreas de conhecimento. De forma ampla, pode-se perceber que as abordagens participativas - que resultam da interação entre pesquisadores, trabalhadores, agentes de governo e comunidades locais - iniciaram a ser destacadas no âmbito da pesquisa acadêmica especialmente a partir da década de 1970 na Escandinávia, Inglaterra, Holanda e Alemanha. Suas origens estão relacionadas à resolução de conflitos (LEWIN, 1946), ações e desenvolvimento da sociedade (REASON, 2002) e colaboração no trabalho (GUSTAVSEN, 1992), conforme destacam Nielsen e Nielsen (2006). No âmbito da pesquisa em ciências sociais identifica-se a busca por perspectivas participativas na abordagem denominada "pesquisa-ação" (action research) - expressão cunhada por Kurt Lewin (1946). Segundo Elliot (1991, p.69, apud TRIPP, 2005) a pesquisa-ação tem como foco, justamente, o "estudo de uma situação social com vistas a melhorar a qualidade da ação dentro dela". Nielsen e Nielsen (2006) defendem que, além da ideia original proposta por Lewin - de aproximar a prática e a teoria - a pesquisa-ação está também orientada ao desenvolvimento de "formas democráticas de conhecimento" e de uma "crítica às estruturas e à cultura autoritária".

\section{PROCEDIMENTOS METODOLÓGICOS E INICIATIVAS ANALISADAS}

Visando validar o conhecimento anteriormente exposto, o presente tópico descreve a experiência de condução de duas iniciativas na Escola de Design da Universidade do Estado de Minas Gerais - UEMG, com enfoque nos métodos e ferramentas utilizados para a realização de cada etapa proposta. Além disso, o papel que o professor precisa desempenhar ao longo do processo de formação, desenvolvimento de habilidades e competências nos estudantes, também foi apurado.

O contexto do projeto é a cidade de Belo Horizonte, em Minas Gerais, sexta capital do Brasil em população, com 2 milhões e 475 mil habitantes e que, ultimamente vem passando por transformações de ordem cultural e social, especialmente no que se refere ao espaço urbano. Com a finalidade de estabelecer uma conexão entre o contexto da cidade e a prática em sala de aula, tais iniciativas buscaram trazer a realidade e a complexidade do meio urbano para o processo de aprendizagem em sala de aula, de modo que os alunos pudessem estabelecer sistemas de experimentação e colaboração a partir de situações reais. A partir daí, discutiu-se sobre quais seriam os ganhos no desenvolvimento desse tipo de abordagem em sala de aula e qual seria o papel do design nesse processo.

As experiências, relatadas a seguir, apontam que o caminho para promover capacidade projetual, interação, desenvolvimento coletivo e analise sistêmica em sala de aula é possível através do pensamento estratégico e de processos participativos. Além disso, tais experiências serviram como referência para gerar as reflexões e possíveis respostas para os questionamentos levantados anteriormente. Ambas as iniciativas partiram de uma base extremamente rica, constituída de entrevistas e insights de cidadãos de Belo Horizonte. 


\subsection{O método Dream:IN na graduação}

O Dream:IN é um projeto internacional, que tem como objetivo a aplicação do design thinking na identificação, desenvolvimento e implementação de políticas públicas e negócios empreendedores. O piloto do projeto no Brasil, adaptado e coordenado pelo Instituto Vivarta (SP), envolveu seis universidades: PUC-Rio, ESPMSão Paulo, UEMG-Belo Horizonte, Unisinos-Porto Alegre, UnB-Brasília e UFMA-São Luís. Participaram um total de 250 estudantes e 20 professores universitários que aprenderam o método e realizaram as duas fases iniciais do projeto localmente, cada qual em sua região, ao longo do primeiro semestre de 2012. A parceria da Escola de Design da UEMG com o projeto Dream:IN se iniciou por meio da disciplina Valorização do Território, ministrada conjuntamente nos cursos de graduação em Design de Produto, Design Gráfico, Design de Ambientes e Artes Visuais. As atividades foram apoiadas pelo Centro de Estudos, Teoria, Cultura e Pesquisa em Design (T\&C Design), pelo Curso de Pós Graduação em Gestão do Design da UEMG e pela empresa ThinkLab.

Alunos de graduação foram a campo, com o desafio de coletar e registrar, na forma de vídeos (Fig.1), sonhos de moradores e trabalhadores em cada cidade. Esta iniciativa estimulou uma grande interação entre alunos e professores e com outras universidades, constituindo uma importante oportunidade para o desenvolvimento de redes e da aplicação de métodos inovadores.
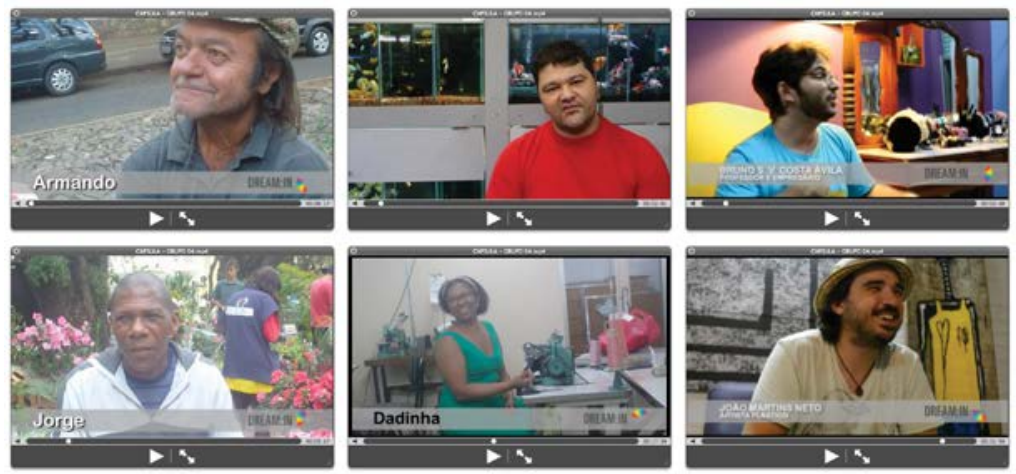

Figura 1: Mosaico de imagens das entrevistas feitas pelos alunos. Fonte: elaborado pelas autoras, 2012.

A disciplina foi concluída com a realização de um encontro que reuniu estudantes, profissionais, empreendedores, especialistas e grandes sonhadores. 0 evento, realizado em junho de 2012, teve como propósito gerar conceitos e soluções, em sessões intensas de ideação, a partir das inspirações e estímulos que os sonhos trouxeram. As figuras 2 e 3 apresentam registros fotográficos do evento com enfoque nos convidados e participantes e nas sessões de ideação, respectivamente.

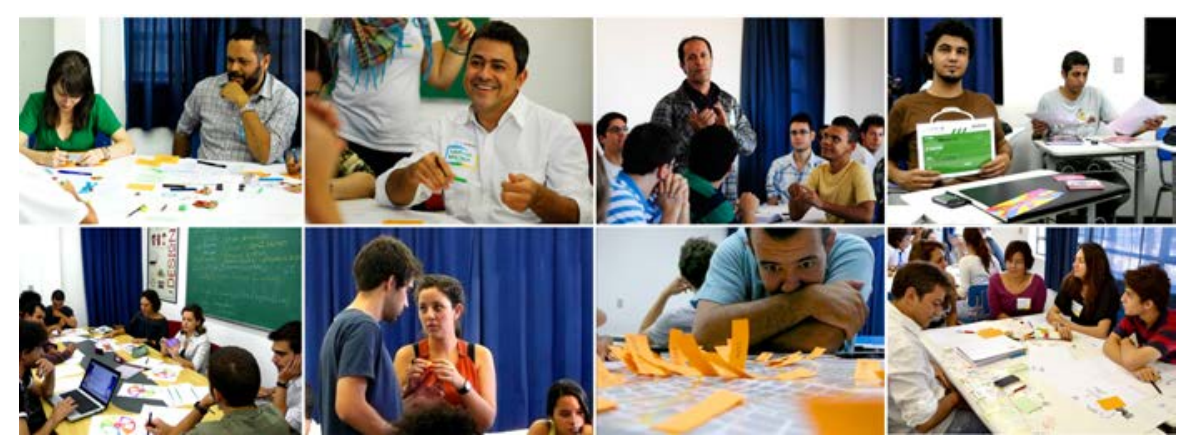

Figura 2: Mosaico de imagens do evento de ideação, com enfoque nos participantes. Fonte: elaborado pelas autoras, 2012. 


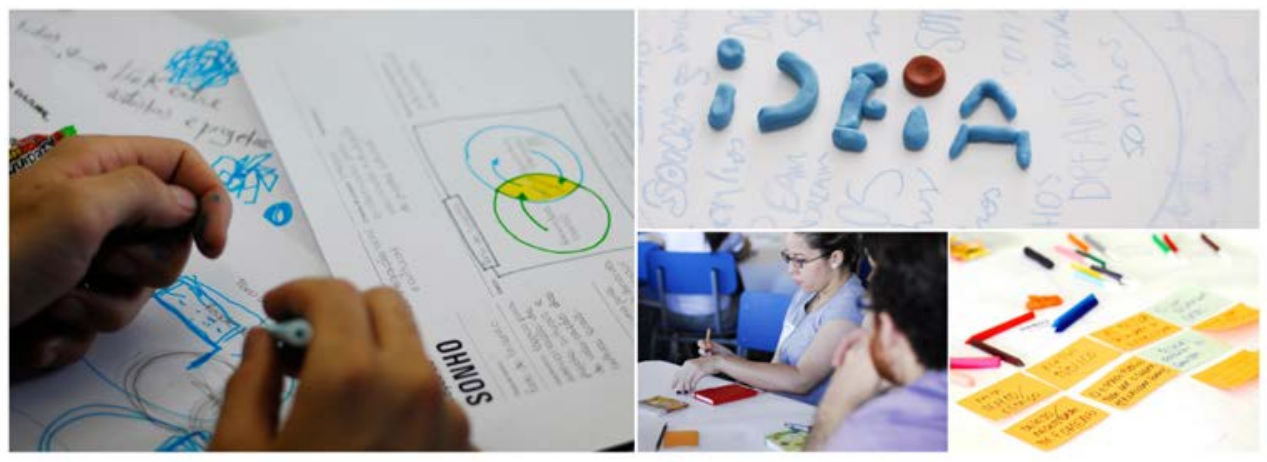

Figura 3: Mosaico com imagens do evento de ideação, com enfoque no material produzido. Fonte: elaborado pelas autoras, 2012.

Vários desafios envolveram as atividades, tais como o preparo e capacitação dos alunos para irem a campo, a adequação das ferramentas do Dream:IN à realidade brasileira e regional, a escassez de recursos financeiros para levantar os equipamentos necessários. No entanto, essas questões foram contornadas com a ajuda da equipe de profissionais e dos professores envolvidos. Assim como o conceito de design thinking refere-se aos processos de pesquisa, criação, prototipagem e intensa interação com o usuário, o método Dream:IN apresenta como ponto de partida o próprio usuário, ou seja, aspirações identificadas nos sonhos de pessoas reais e não mais na identificação de problemas como em outros métodos, o que contribui de maneira efetiva para a potencialização dos resultados.

\subsection{Cocriação no Mestrado}

A segunda iniciativa se deu no âmbito do Mestrado em Design, Inovação e Sustentabilidade da UEMG, durante os primeiros semestres dos anos de 2013 e 2014, inserida na disciplina Cadeia de Valor e Valorização de Recursos Locais, ministrada por Lia Krucken. A primeira etapa da disciplina, de base teórica, teve como objetivo discutir as competências do design e do profissional no contexto contemporâneo e se deu por meio de debates e seminários, com a participação de convidados especiais. Tais discussões propiciaram aos alunos, posteriormente, embasamento para compreender o papel de ligação do design e sua ação profícua enquanto propulsor de estratégias de projetos e negócios.

A segunda etapa consistiu em desenvolver uma proposta, em grupo, de uma ideia a ser implementada na forma de produto, serviço ou combinação de produto e serviço. A figura 4 apresenta um esquema com as principais fases do processo percorridas pelos alunos.

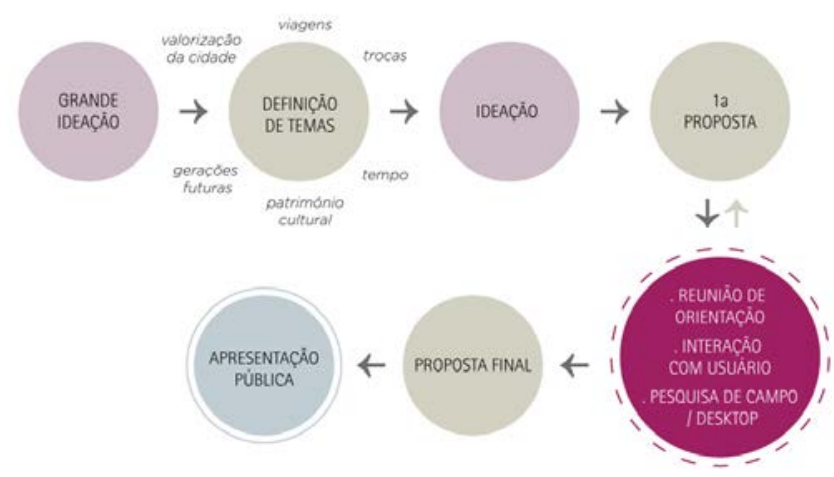

Figura 4: Esquema com as fases de desenvolvimento do projeto. Fonte: elaborado pelas autoras, 2014. 
Inicialmente, os alunos participaram de uma etapa de ideação, tendo como fonte de inspiração insights categorizados em temáticas como viagem, valorização da cidade e do patrimônio cultural urbano, valorização do tempo e do bem estar, dentre outros (Fig.5). A partir de brainstorming, vários temas foram levantados tendo em vista seu potencial de transformação social e a partir desse ponto, os grupos foram definidos. Já com o enfoque na temática e contexto definidos, foi possível para os grupos aprofundarem na busca de dados que permitissem intensa reflexão acerca dos problemas levantados, além de boa compreensão da situação, para então realizar suas próprias sessões de ideação. Tais encontros de orientação tinham como objetivo gerar alternativas de soluções que fossem mais adequadas ao contexto. A solução escolhida pelo grupo era então transformada em proposta de projeto e apresentada aos professores e colaboradores da disciplina, com o intuito de gerar discussões construtivas para aprimoramento do trabalho.
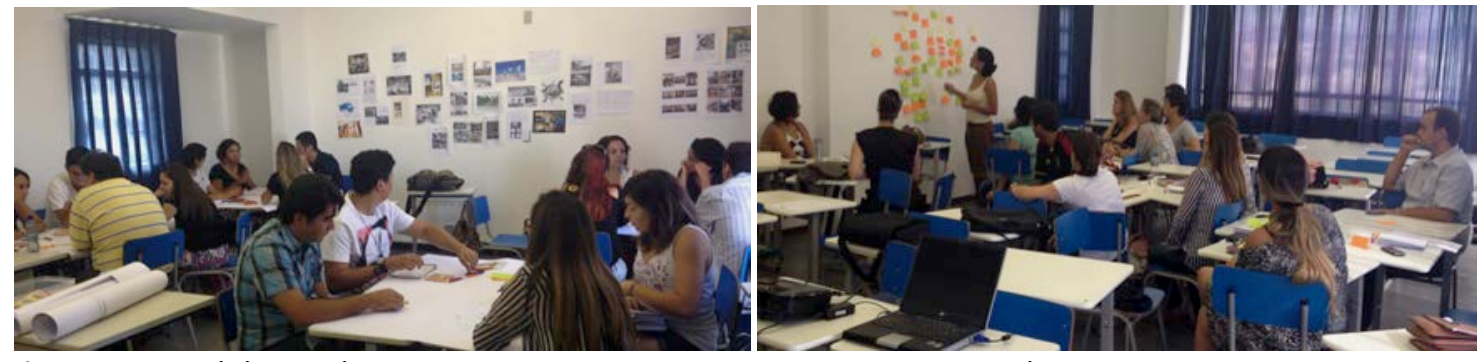

Figura 5: Painel de insights iniciais para o projeto. Fonte: acervo Lia Krucken, 2014.

A partir de ferramentas de interação com o usuário, pesquisa de campo, análise de viabilidade, modelagem de negócios, dentre outras, foi possível validar a proposta da solução escolhida e buscar estratégias para tangibilização e visualização da ideia. Concretizar a solução significava torná-la realidade e o grupos o fizeram a partir de ferramentas disponíveis, como: storytelling, storyboard, visualização de cenários, definição de personas, e outros métodos, que serão abordados no tópico seguinte.
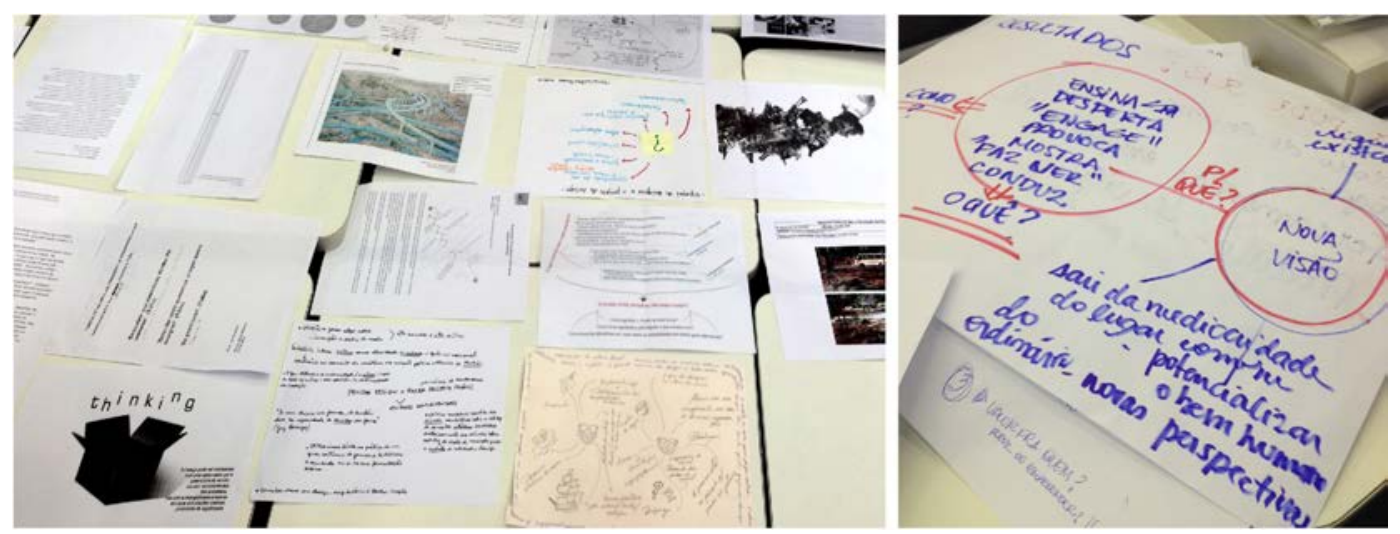

Figura 6: Fotos de registro de duas etapas do processo: debates e ideações. Fonte: acervo das autoras, 2013 e 2014. 


\section{FOCO NO PROCESSO E NAS FERRAMENTAS DE DESIGN}

Nas iniciativas apresentadas anteriormente, o uso de diversas ferramentas foi citado enquanto fator crucial não só para a viabilização de uma ideia como também nos processos de concretização e validação. Em ambientes de projeto cujas etapas metodológicas nem sempre são lineares e os cenários não podem ser previstos, na maioria das vezes, os alunos devem aprender a lidar com a complexidade e entender que o contexto é passível de transformação à medida que o projeto evolui. Esse aspecto se apresenta desafiador para o professor, em seu papel motivacional e de orientação e aceleração do processo de síntese e fechamento das ideias. Também é desafiador para os alunos, que precisam lidar com tamanha liberdade de criação e, ao mesmo tempo, com a frustração, natural do processo criativo, principalmente em momentos em que algum resultado não sai conforme planejado e deve-se retroceder em alguma etapa.

Neste contexto, em que normalmente não existe uma única resposta para o problema em questão, a saída pode estar na utilização consciente de determinados recursos e ferramentas que auxiliem na identificação das soluções mais adequadas para cada etapa do processo.

A figura 7, a seguir, apresenta as principais etapas do processo de design organizadas, de maneira esquemática, em quatro áreas e dispostas de forma a indicar a orientação da leitura da esquerda para a direita, e de cima para baixo. O processo de qualquer projeto de design caminha do saber ao fazer e do abstrato ao real. Tal orientação, entretanto, não restringe as fases internas do processo a um único caminho e, inclusive, a seta presente no centro do esquema reforça tal ideia. Nos quadrantes da esquerda estão listadas atividades mais abrangentes, como análise e pesquisa e que tem como objetivo ampliar e aprofundar a visão que se tem sobre determinada questão. Já nos quadrantes dispostos à direita, se localizam tarefas que indicam um foco, como propor protótipos e por isso, são convergentes.

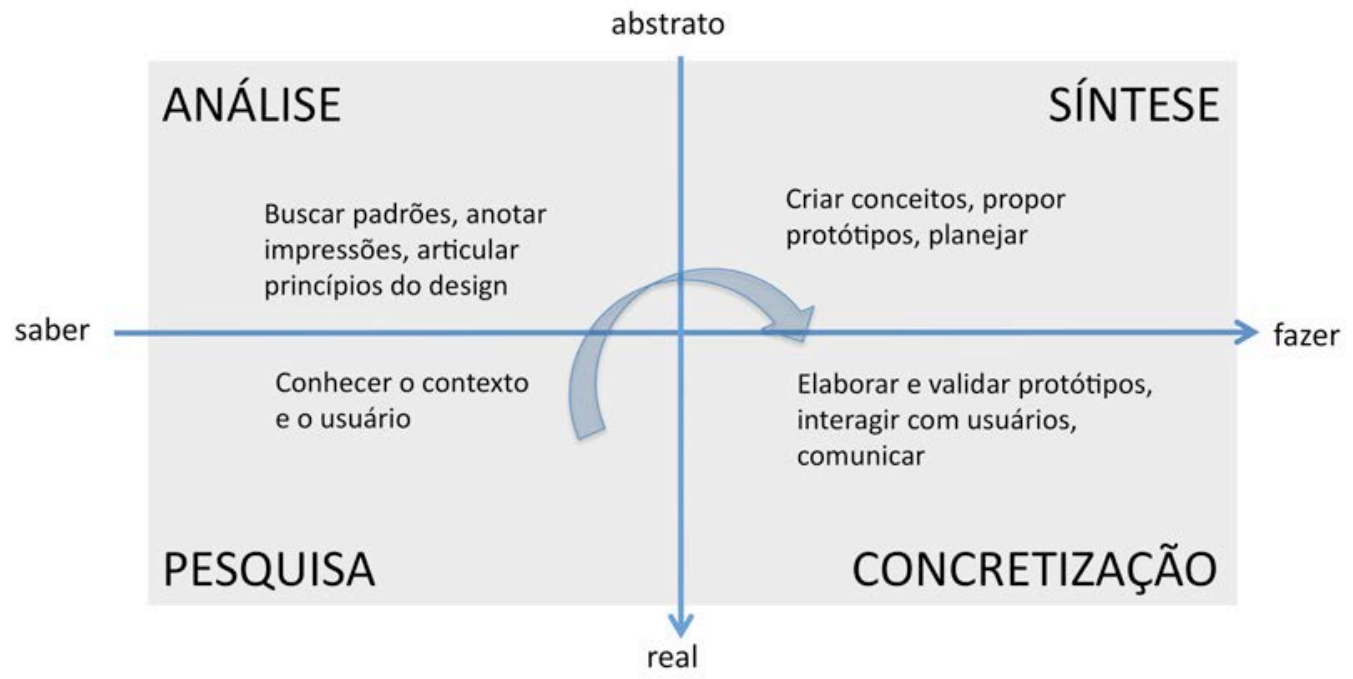

Figura 7: Principais etapas do projeto de design. Fonte: Elaborado por Krucken (2013) a partir de Owen (2005), Kumar (2013) e processo de inovação da Ideo.

Com o objetivo de demonstrar as ferramentas mais indicadas para cada etapa do processo foi realizado um mapeamento e o resultado é apresentado na figura 8. 


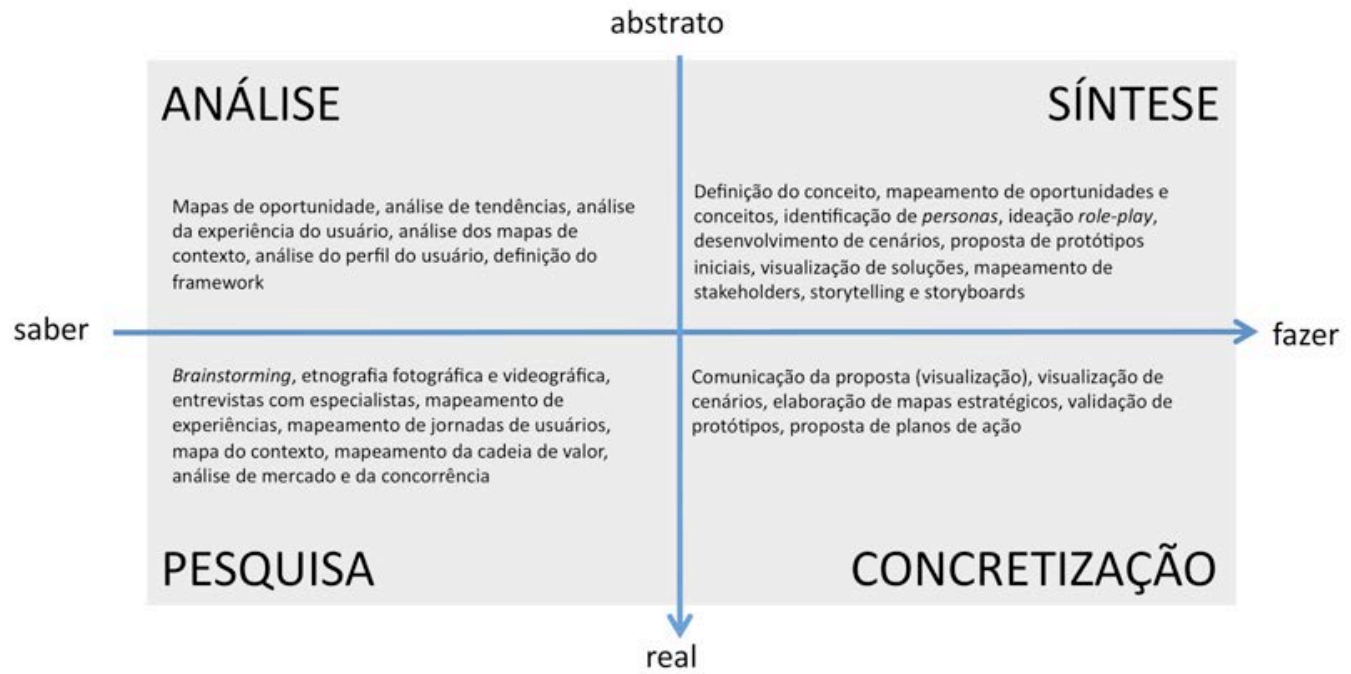

Figura 8: Identificação das ferramentas em cada uma das etapas do projeto de design. Fonte: Elaborado por Krucken (2013) a partir de Owen (2005), Kumar (2013) e processo de inovação da Ideo.

Assim, no contexto dinâmico da sala de aula os professores devem possuir habilidade de condução do processo e domínio das ferramentas, para então, sugerir as mais adequadas ao cenário em questão. Sobre as competências necessárias aos facilitadores desse processo, entende-se que seu papel é o de abordar o conteúdo de forma sistemática e objetiva, buscar fortalecer o desenvolvimento do pensamento estratégico e promover um espaço de experimentação sempre que possível. A importância da discussão sobre o papel do espaço de ensino em design no contexto contemporâneo é destacado por Santiago e Coutinho (2013).

O desafio de proporcionar o "aprendizado pela experiência" no ensino em design é também destacado por Penati (2012, p.57), dentre outros autores. A autora aponta a importância de incorporar métodos e oportunidades para que os alunos possam "aprender pela experiência" e, assim, desenvolver habilidades operacionais e práticas. Essas oportunidades - continua a autora, citando (Schön, 1993) - também devem estimular os alunos a desenvolver habilidades relacionadas à análise crítica e à comunicação e habilidades comportamentais - "todos ingredientes que intervêm na solução de problemas". Por fim, a autora destaca que o design - como disciplina aberta - "seja talvez destinado a manter abertas as áreas de pesquisa relacionadas à sua prática, dentre elas, a prática de ensinar, a qual desempenha um papel crítico no desenvolvimento das fundações dessa profissão". 


\section{CONSIDERAÇÕES FINAIS}

Ambas as iniciativas apresentadas revelaram possuir grande potencial para gerar ideias relacionadas à transformação social. As aspirações e perspectivas das pessoas, incluindo dos próprios participantes no processo, como cidadãos, configuram um material extremamente rico e inspirador, que, em um ambiente ideal propício a cocriação, se transforma em ideias igualmente inspiradoras e inclusivas. Por esse viés, entende-se que o ensino do design, com foco no desenvolvimento de pensamento estratégico e processos participativos inseridos no contexto de atuação, possui grande potencial para gerar sensibilização e inovação social.

Ao longo do processo de pesquisa e implementação das iniciativas, três questões foram consideradas de fundamental importância para se conquistar um resultado considerável no ensino e na qualidade dos projetos apresentados:

a) Foco e registro do processo - refere-se ao desafio constante de manter o foco no processo e a importância de se registrar todas as etapas e ferramentas utilizadas ao longo do projeto;

b) Integração do designer com agentes locais e cidadãos para desenvolver formas de inovação colaborativa, que resultam em novos serviços para a vida cotidiana, reforçando o caráter interdisciplinar do design;

c) Necessidade de competências relacionadas à interatividade, à habilidade de escuta e ação em diferentes contextos, à gestão da informação, ao desenvolvimento coletivo, à análise sistêmica, dentre outras.

Além disso, por se tratar de uma abordagem inovadora para o ensino do design buscou-se realizar uma análise dos pontos críticos e questões em aberto levantados ao longo do processo. Dentre as questões levantadas, destacam-se algumas: "O sistema educacional está preparado para implementar métodos que se adaptam a condições e cenários variáveis, ou seja, que considerem a experimentação e a necessidade de flexibilidade ao longo do processo de design?"; "Quais fatores interferem nos resultados dos processos participativos e de cocriação?"; "Quais as competências necessárias aos professores facilitadores do processo?". A discussão destas questões visa contribuir para o entendimento das competências necessárias à formação de profissionais dinâmicos, que possam oferecer soluções integrando diferentes atores e perspectivas.

Por fim, torna-se cada vez mais clara a importância de considerar a dimensão social nos projetos e os impactos socioculturais das soluções propostas. A incorporação de abordagens participativas no ensino em design pode contribuir para integrar perspectivas mais amplas ao longo da atividade projetual e convergir interesses de diferentes atores da sociedade.

\section{AGRADECIMENTO}

Aos professores Mario Santiago, Oswaldo Coutinho e Marco Túlio Boschi, pelas preciosas discussões e inspirações. Aos alunos da graduação e do Mestrado em Design, Inovação e Sustentabilidade, pela ativa participação e dedicação às atividades propostas. A equipe Dream:in Brasil, EUA e Índia pela rica experiência de participar em um projeto colaborativo internacional. À Escola de Design da UEMG e ao Programa de Pós Graduação em Design pelo apoio institucional. 


\section{REFERÊNCIAS}

CIPOLLA, C. Design, inovação social e sustentabilidade. In: Moraes, D; lida, I.; Dias, R. (Org.). Cadernos de Estudos Avançados em Design: Inovação. Barbacena: EdUEMG, 2012, p. 65-79.

GUSTAVSEN, B. Dialogue and development. Social science for social action. Assen: Van Gorcum, 1992.

KRUCKEN, L. Competências para o design na sociedade contemporânea. In: DE MORAES, D.; KRUCKEN, L. (Org.). Design e Transversalidade. 1 ed. Belo Horizonte: Santa Clara, 2008, v. 1.

KRUCKEN, L., BOSCHI, T. Guia para apresentação dos projetos de design estratégico. Notas de aula. Disciplina "Cadeia de valor e valorização de recursos locais", Universidade do Estado de Minas Gerais, Belo Horizonte, Maio de 2013.

KUMAR, V. 101 design methods: a structured approach for driving innovation in your organization. New Jersey: Wiley, 2012.

LEWIN, K. Resolving social conflicts. New York: Harper, 1946.

MANZINI, E. El diseño como herramienta para La sostenabilidad medioambiental y social. In: MACDONALD, S. (org.) Design issues in Europe today. Barcelona: BEDA, 2004.

MURRAY, R., CAULIER-GRICE, J., MULGAN, G. The Open Book of Social Innovation. The Young Foudation, 2010. Disponível em <http://youngfoundation.org/wpcontent/uploads/2012/10/The-Open-Book-of-Social-Innovationg.pdf>

NIELSEN, L. Personas in Co-creation and Co-design. In: Proceedings of the 11th Danish Human-Computer Interaction Research Symposium (DHRS2011). Copenhagen Business School Press, 2011. p. 38-40.

NIELSEN, K. A.; NIELSEN, B. S. Methodologies in Action Research. In NIELSEN, K. A.; SVENSSON, L. G. (org.) Action and Interactive Research. Beyond practice and theory. The Netherlands: Shaker Publishing, 2006.

OWEN, C. Design Thinking. What It Is. Why It Is Different. Where It Has New Value. Speech at International Conference on Design Research and Education for the Future. Chicago's Institute of Technology, 2005.

PENATI, A. Research for design education: some topics. In: FORMIA, E. M. (org). Innovation in design education. Theory, research and processes to and from a Latin perspective. Torino: Umberto Allemandi, 2012.

PRAHALAD, C.K., \& RAMASWAMY, V. The Co-creation experiences: the next practice in value creation. In: Journal of Interactive Marketing. v. 18, n. 3, p. 5-14, 2004. 
REASON, P. Justice, sustainability, and participation: Inaugural professorial lecture. In Concepts and Transformation vol 7 number 1; 2002. Disponível em: http://www.peterreason.eu/Papers/InauguralLecture.pdf

SANDERS, E. B. N.; STAPPERS, P. J. Co-creation and the new landscapes of design. CoDesign, 4, (1), 2008, p. 5-18.

SANTIAGO, M.; COUTINHO, O. Debate sobre o papel do espaço de ensino em design no contexto contemporâneo. Notas de aula. Escola de Design - Universidade do Estado de Minas Gerais, 2013.

SCHÖN, D. Il professionista riflessivo. Per una nuova epistemologia della pratica professionale. Bari: Dédalo, 1993.

TEIXEIRA, J. C. Latin American markets as design labs. Strategic Design Research Journal, 2(2): 69-72 julho-outubro 2009.

THACKARA, J. In the bubble: designing in a complex world. Cambridge: MIT, 2005.

TRIPP, D. Pesquisa-ação: uma introdução metodológica. Educ. Pesqui., São Paulo , v. 31, n. 3, Dec. 2005. 